\title{
Miradas poéticas sobre la sociedad de consumo: Roberto Santoro y Décio Pignatari
}

Poetic looks about the consumer society. Roberto Santoro and Décio Pignatari

Visões poéticas sobre a sociedade de consumo: Roberto Santoro e Décio Pignatari

María Agustina Catalano*

\section{Resumen}

Este artículo se propone analizar diferentes usos poéticos de objetos de consumo, en particular de la famosa bebida Coca-Cola. Tomaremos como punto de partida "beba coca-cola" (1958) de Décio Pignatari y "saciedad del consumo" y "tome coca cola" (1975) de Roberto Santoro, aunque el corpus sea más vasto y se extienda hasta el presente. Nos interesa pensar cómo se resignifican la cultura de masas y la ideología antiimperialista (tan presente durante el periodo latinoamericano 60 -70), y la relación entre palabra escrita, oralidad e imagen, poniendo atención a las divergencias y continuidades posibles entre Argentina y Brasil.

Palabras clave: poesía, cultura, consumo, vanguardia.

\begin{abstract}
This article aims to analyze different poetic uses of consumer objects, in particular the famous CocaCola drink. We will take as a starting point "beba coca-cola" (1958) by Décio Pignatari and "saciedad del consumo" and "tome coca cola" (1975) by Roberto Santoro, although the corpus is broader and it extends to the present. We are interested in thinking about how mass culture and the antiimperialist ideology (present during those years in Latinoamérica) are resignified, and the relationship between written word, orality and image, paying attention to the divergences and possible continuities between Argentina and Brazil.
\end{abstract}

Keywords: poetry, culture, consume, vanguard.

\begin{abstract}
Resumo
Este artigo propõe analisar diferentes usos poéticos de objetos de consumo, em particular a famosa bebida Coca-Cola. Nosso ponto de partida é "beba coca-cola", de Décio Pignatari (1958), e "saciedad del consumo" e "tome coca cola", de Roberto Santoro (1975), embora o corpus seja mais amplo e possa se estender até o presente. Queremos pensar como são ressignificadas a cultura de massas e a ideologia anti-imperialista (muito presente durante o período latino-americano dos anos 60-70), e a relação entre palavra escrita, oralidade e imagem, focando nas possíveis divergências e continuidades entre Argentina e Brasil.
\end{abstract}

Palavras-chave: poesia, cultura, consumo, vanguarda.

Desde muy temprano, la literatura registró el proceso de aparición y proliferación de objetos, productos y apartos, como las máquinas, las telecomunicaciones y los transportes propios de la sociedad industrial que se movía a ritmos impensados. En este artículo, nos detendremos en una clase en particular: los llamados objetos de consumo, que suponen, aún hoy, nuevas formas de relación entre el sujeto contemporáneo y el entorno que lo rodea. Jean Baudrillard los define del siguiente modo:

El consumo no es ni una práctica material ni una fenomenología [...] no se define ni por el alimento que se digiere, ni por la ropa que se viste, ni por el automóvil de que uno se vale, ni por la sustancia oral y visual de las imágenes y de los mensajes, sino por la organización de todo esto en sustancia significante [...] El consumo es una actividad de manipulación sistemática de signos (2016, p. 224).

\footnotetext{
* Universidad Nacional de Mar del Plata, Mar del Plata, Buenos Aires, Argentina. (Dorcid.org/0000-0001-5684-3363. E-mail: a_catalano@outlook.com.ar
} 
Existe abundante bibliografía sobre esta cuestión, pero nos interesa ahora resaltar las ideas del consumo como sistema de significaciones y del objeto en tanto signo. Se trata de una propuesta que no prioriza la dimensión material que Marx sí había tenido en cuenta para la elaboración del concepto de "fetichismo de la mercancía" en su obra El capital. ${ }^{1}$ En esa línea, podemos afirmar que la bebida Coca-Cola es una de las expresiones por antonomasia (no la única, claro $)^{2}$ de este sistema cultural, en la medida en que da vuelta la lógica moderna de oposición entre modelo y serie: se nos ofrece como un modelo (objeto personalizado, singular, "con estilo") pero en forma serial. Esto es lo que Baudrillard llama "el milagro del sistema" (2016, p. 164) o la "falsa elección en la abundancia espectacular", en palabras de Guy Debord (2006, p. 53). Al mismo tiempo, Coca-Cola es quizás el mejor ejemplo de esta aparente ideología democrática que ofrece a todos por igual - gracias a la serie - la posibilidad de acceder al modelo. En consonancia, Bauman (2007) diferencia el "consumo" de lo que entiende por "consumismo". Mientras que el primero implicaría un hecho trivial, que si se lo reduce a su forma arquetípica (el ciclo metabólico) sería una simple condición biológica permanente y, por lo tanto, desligado de la historia, el segundo es un acuerdo social que resulta de la reconversión de nuestros deseos, ganas o anhelos en "la principal fuerza de impulso y de operaciones de la sociedad" (Bauman, 2007, p.43-76). Si para Debord (2006, p. 24) la mercancía se aparta del sujeto y se convierte en representación, en espectáculo, Coca-Cola es entonces signo de autoidentificación individual, distinción o pertenencia, emblema de la american way of life, y, simultáneamente, desecho, despojo, restos de plástico o de vidrio. En lo que respecta al arte, sabemos que tuvo un recorrido bastante amplio a través del siglo $\mathrm{XX}$ y que su punto más álgido fue durante las llamadas neovanguardias; en esta figura se simbolizan y pueden volverse visibles problemáticas económicas, políticas y culturales de la sociedad contemporánea.

Ana Porrúa (2013) llamó "archivo de la imaginación poética" a la reunión de ciertos fragmentos, materiales e imágenes, que se repiten en la poesía y se interpelan entre sí. Podríamos considerar este planteo bastante cercano al del "Atlas" (Warburg, 1924) 3 o a la cartografía; es decir, el encuentro o la evocación de analogías, de correspondencias. En ese sentido, encontramos que artistas y escritores latinoamericanos toman como materiales a la bebida Coca-Cola y al discurso publicitario que la envuelve. Nos preguntamos entonces, a partir de la imagen del archivo, acerca de la posibilidad de que este uso literario/artístico revele algo más que una decisión estética compartida durante varias décadas por muchos escritores y artistas. Para ello, nos detendremos en un período que va desde fines de los cincuenta a los setenta, es decir, en el poema "beba coca cola" (1958) del brasileño Décio Pignatari (1927-2012), y "sociedad de consumo" y "tome Coca Cola" (No negociable, 1975) de Roberto Santoro (1939 - desaparecido en 1977). Proponemos este recorte dado hay una continuidad estética y poética entre ellos y también porque entendemos el bloque 60-70 como un periodo "con espesor histórico propio" (Gilman, 2003, p. 32) con diversos puntos de contacto entre Brasil y Argentina, como por ejemplo, haber sufrido los efectos del

\footnotetext{
${ }^{1}$ No es nuestro objetivo examinar la relación entre la teoría marxista y el planteamiento de Baudrillard; solo nos interesa establecer una distancia entre ambos pensadores, por un lado, de índole de distancia temporal e histórica, pero también interpretativa, ya que pensar los objetos más allá de su acepción material implicará un análisis de tipo semiótico. El filósofo francés dice que lo que hoy consumimos es una relación, o, mejor dicho, la idea de una relación de consumo, y no los objetos, que son sólo una mediación obligada. Agrega: "Tocamos aquí, en su culminación, la lógica formal de la mercancía analizada por Marx: tal y como las necesidades, los sentimientos, la cultura, el saber, todas las fuerzas propias del hombre están integradas como mercancías en el orden de producción, se materializan en fuerzas productivas para ser vendidas; hoy en día, todos los deseos, los proyectos, las exigencias todas las pasiones y todas las relaciones se abstraen (o se materializan) en signos y en objetos para ser comprados y consumidos (2016, p. 225).

${ }^{2}$ La bebida originaria de Atlanta, Estados Unidos, apareció por primera vez en el mercado en 1886, según su página oficial (www.coca-cola.com/global). El libro Dios, patria y Coca Cola (publicado por primera vez en 1993), algo así como una biografía no autorizada de la marca, muestra algunos números que podrían ayudar a dimensionar el impacto de la empresa y del producto en la cultura no solo norteamericana sino mundial. Por ejemplo, que se comercializa en más de 200 países o que la compañía invierte más de cuatro millones de dólares en publicidad y marketing. El autor afirma incluso que después de la expresión "O.K”, Coca-Cola es una de las palabras más conocidas en el mundo (Pendergrast, 2000).

3 “Atlas Mnemosyne" es una obra del alemán Aby Warburg (1866-1929) iniciada en 1924 y que quedó incompleta a causa de su muerte. El proyecto contenía más de 60 "tablas" que recopilaron, en total, más de dos mil imágenes que se conectan e interpelan entre sí como una red. La idea se contrapone con la del catálogo, que propone un orden cerrado y consecutivo. Georges Didi Huberman fue curador de "Atlas" en el año 2010.
} 
terrorismo de estado y los respectivos golpes cívico-militares. ${ }^{4}$ Por último, hay otras obras que también podrían incluirse en un corpus latinoamericano mayor: "Alegria, alegria" (1968) de Caetano Veloso, "Inserciones en circuitos ideológicos: Proyecto Coca Cola" ${ }^{5}$ (1970) de Cildo Meireles, "Colombia" (1977) de Antonio Caro, "Mensaje en una botella" (artefacto, 1971) y "Padre nuestro - Tome Coca Cola" (poema visual, 1999) de Nicanor Parra, entre otros.

Décio Pignatari conformó junto a los hermanos Haroldo de Campos (1929-2003) y Augusto de Campos (1931-), entre otros, la denominada "poesía concreta", un movimiento de corte vanguardista y experimental que concebía la palabra poética como "un campo magnético de posibilidades, un objeto dinámico, una célula viva, un organismo completo" (Campos, 1956). Por su parte, Roberto Santoro publicó su primer poemario, Oficio desesperado, en 1962 y después, casi ininterrumpidamente, sus otros títulos hasta 1977, fecha en que un grupo de tareas de la dictadura militar lo secuestró de la escuela en la que trabajaba como jefe de preceptores. Dejó algunos proyectos y libros inconclusos que se editaron y compilaron recién en 2008, con la publicación de su obra poética completa.

A priori podemos advertir que los poemas de ambos autores tienen algunas similitudes formales, como el uso minimalista de los versos cortos y la ausencia de convenciones ortográficas como las mayúsculas y los signos de puntuación. Esto puede relacionarse, por un lado, con el diálogo que los dos establecen con el discurso publicitario, que privilegia la brevedad del mensaje para que sea rápidamente memorizado e incorporado por los espectadores. Por el otro, con la ruptura de las formas poéticas tradicionales. Recordemos que ya desde la década del 50 se había instalado en Europa y Estados Unidos la llamada "neo vanguardia" (término acuñado por Peter Bürger en Teoría de la vanguardia), es decir, movimientos, colectivos y/o artistas que retomaron algunas de las técnicas y herramientas de la vanguardia histórica, como el grupo Oulipo (Francia), el Arte Pop y Arte Conceptual (Estados Unidos e Inglaterra, en sus comienzos), el Arte Pobre (Italia) o el Nuevo Realismo (confluencia de diferentes artistas europeos, principalmente franceses). La región se hizo eco de estas expresiones, lo que no implica una importación sin cambios o alteraciones. Santoro bromeaba al respecto en una entrevista del año 1973, afirmando que era surrealista, pero eso quería decir "realista del sur" (Vásquez, 2003, p.36). Era un poeta de raigambre popular y de origen plebeyo, que circuló en cierta periferia y tejió lazos estrechos con el lirismo característico del tango, al menos durante su primera etapa. No negociable es el final de su recorrido, donde leemos con mayor presencia su singularidad, su propia voz. En esta última fase, incorporó de manera constante todos los referentes relativos al mundo de las comunicaciones y el espectáculo, pero tamizándolos con operaciones propias del humor negro y la comicidad. Gonzalo Aguilar plantea que la repetición de la neovanguardia debería ser pensada también en términos de desvío y diferencia ya que, si bien fue "miméticamente vanguardista", los resultados conseguidos a partir de sus intervenciones transformaron ampliamente a la vanguardia histórica (2003, p. 63). Por ende, podríamos hablar de una doble correlación en nuestra neovanguardia latinoamericana, en tanto dialoga con el modelo europeo-norteamericano y al mismo tiempo con sus antecesores vanguardistas latinoamericanos. Otilia Beatriz Fiori Arantes identifica algunas referencias de la vanguardia de los años 60-70 en Brasil: Duchamp, el dadaísmo, el surrealismo, pero más directamente, el modernismo brasileño personificado en Oswald de Andrade. La divergencia principal reside en que:

En los años 20 todavía se trataba del "sueño brasileño", se tenía una visión predominantemente prospectiva, optimista, utópica; ya en los años 60 lo que domina es el gusto amargo de la desilusión. Si en aquellos tiempos también había, junto con la apuesta a

\footnotetext{
${ }^{4}$ Creemos poco probable que Pignatari y Santoro se hayan conocido y/o leído. Pretendemos leer esta superposición o montaje más allá de los datos fácticos (en todo caso, que los textos nos remitan), en el sentido de una "archifilología" (Antelo, 2013, p. 276), es decir, sin atender al origen o a la originalidad de estos usos, tampoco homologarlos, más bien poniendo el énfasis en las distancias, aquello que los conecta y al mismo tiempo los distingue.

${ }^{5}$ La intervención consistía en alterar los envases de Coca-Cola (tal cual eran comercializados) agregando preguntas, ilustraciones o consignas como "iLos yanquis se van a casa!" en una tipografía blanca que imitaba las inscripciones típicas de la marca de la botella. En otros casos, eran preguntas poéticas o filosóficas. Meireles creó así más de mil modelos.
} 
la modernidad y a la necesidad de construir un Brasil nuevo, una insatisfacción respecto de la realidad, el atraso, el provincianismo, se buscaba, no obstante, preservar los valores nacionales, nativos, contra la desfiguración que la modernidad podría traer. En la década del 60, habiendo pasado por las enseñanzas del arte abstracto, el arte brasileño ya se encuentra bastante alejado de la temática nacional y popular (Arantes, 2000, p. 221-222).

En el caso argentino, gran parte de los artistas visuales, músicos y escritores se nuclearon en torno al Instituto Di Tella, con sede en la ciudad de Buenos Aires, fundado en 1958 y clausurado por la dictadura de Onganía en 1970. Para Ana Longoni, la mayoría de los proyectos y programas artísticos del periodo se desprendieron del encuentro de dos conceptos: vanguardia y revolución. Este último se relocaliza en Argentina, no en términos de una revolución específica, sino de un "clima triunfalista instalado en amplios sectores sociales acerca de la inminencia o proximidad de una revolución” (Longoni, 2014, p. 21-22). Movilizaciones populares, rebeliones, organizaciones políticas y el crecimiento de la guerrilla urbana contribuyeron a reforzar ese espíritu. Se resignificaron los happenings, los ready-mades, el collage y se crearon nuevas técnicas y modalidades como, por citar un ejemplo, los vivo-dito de Alberto Greco. ${ }^{6}$

En efecto, la Coca-Cola no encarna o significa lo mismo para los artistas y escritores latinoamericanos que para Andy Warhol o el arte pop norteamericano. Si bien se trata, en el caso de Warhol, de obras estrictamente visuales, no se hace evidente la caracterización crítica o negativa de Coca-Cola. ${ }^{7}$ De hecho, la estimaba afirmando que era genial y democrática porque la compraban tanto los ricos como los pobres (1975, p. 100). Además fue convocado por la empresa para participar del lanzamiento de la "New Coke" en 1985. El gesto es lo que parece ponerse en el centro: tomar objetos de la cultura masiva y colocarlos en una obra de arte, en un museo, a partir de la repetición. La reproducción serial y su capacidad de expansión rápida y amplia (al igual que las sopas Campbell) es capturada en la imagen y admirada. En cambio, estos poemas se enmarcan en un proceso de consolidación de un fuerte sentimiento antiimperialista y de rechazo a toda potencia colonial, que tuvo como principal impulso la revolución cubana de 1959 (Gilman, 2003, p. 44-56). La sociedad de consumo, el acceso a determinados bienes, la distinción social o de clase no se dan en países como Argentina o Brasil del mismo modo que en el Europa o EEUU, dado que todavía el desarrollo industrial está en curso. Sin embargo, hay una relación conflictiva con ese "progreso capitalista", que suele fluctuar entre el rechazo y el anhelo de una modernización augurada por distintos gobiernos. Tanto Argentina como Brasil atraviesan, a fines de los 50 y principios de los 60, procesos de cambio a nivel económico y cultural. En el primer caso, bajo la presidencia de Frondizi (19581962) quien, entre otras cosas, promovió la radicación de empresas multinacionales en el país; y en el segundo, durante la gestión de Juscelino Kubitschek (1956-1961), que también tenía una propuesta de tipo desarrollista. ${ }^{8}$

Ahora bien, los títulos "tome coca cola" y "beba coca cola" son casi idénticos, debido al uso de la marca registrada y el modo imperativo que abre una serie de asociaciones y relaciones posibles con otras voces o imágenes. Ambos consignan el mismo slogan publicitario de la marca ("Drink Coke"), ${ }^{9}$ según su respectiva traducción. Resuena el discurso publicitario que sugiere o aconseja al espectador "beber", en el caso de Pignatari, o "tomar", en el caso de Santoro, es decir, consumir o comprar el producto no tanto como una orden sino más bien como un consejo, una sugerencia. Esta estrategia es recurrente en las publicidades, siendo muchas veces

\footnotetext{
${ }^{6}$ Eran señalamientos realizados en las calles realizados mediante un trazado con tiza alrededor de personas, objetos, animales o situaciones (por ejemplo, un obrero yendo a su trabajo, una mujer colgando ropa) (Longoni, 2014, p. 31-33).

${ }^{7}$ Nos referimos a las obras "3 Coke bottles" y "Green Coca Cola bottles", ambas de 1962.

${ }^{8}$ Carlos Altamirano (1998) caracteriza al desarrollismo como el plan o proyecto económico que buscaba superar el modelo agroexportador a través de una paradójica combinación de inversiones extranjeras con intermediación estatal. Para él, se trataba más de un "espíritu generalizado" que de un grupo ideológico en particular (p. 79) y aunque la propuesta no era nada novedosa, el discurso y la terminología utilizada, sí.

${ }^{9}$ Según el sitio oficial de Coca-Cola es uno de los primeros slogans utilizados, data de 1886, y fue reutilizado en muchos países a lo largo de los años y algunas veces acompañando a otros. Ver: "Coca-Cola slogans through the years", disponible en: http://www.coca-colacompany.com/coca-cola-slogans-through-the-years. Último acceso en 16 abr. 2018.
} 
utilizada como parte de frases o slogans, siempre acompañada de contenido o elementos visuales (fotografía, colores, etc.). La aparente invitación no es inocente ni desinteresada; si nos adentramos en los poemas vemos que, a partir de dos procedimientos diferentes que describiremos más adelante, ambos muestran los intersticios de un enunciado que se pretende despojado y simple, pero esconde intereses no sólo económicos sino también políticos e ideológicos. Además, podemos leer el imperativo en un sentido condicional, o sea que si se realiza o lleva a cabo la acción, habrá determinadas consecuencias. En una publicidad esos efectos serían 'positivos', por ejemplo, la promesa de la obtención de placer o de cierto éxito social. Pero Coca-Cola se asocia en los textos a una serie de elementos negativos que podrían causar en el sujeto estados de podredumbre y anestesia.

En el poema de Pignatari, hay un desplazamiento visual pero también fonético y morfológico que provoca el desprendimiento del sustantivo "cloaca" del nombre propio CocaCola (aunque sin mayúsculas y, por ende, en el mismo plano que los demás elementos), como un juego de palabras, un trabalenguas, un crucigrama (Figura 1).

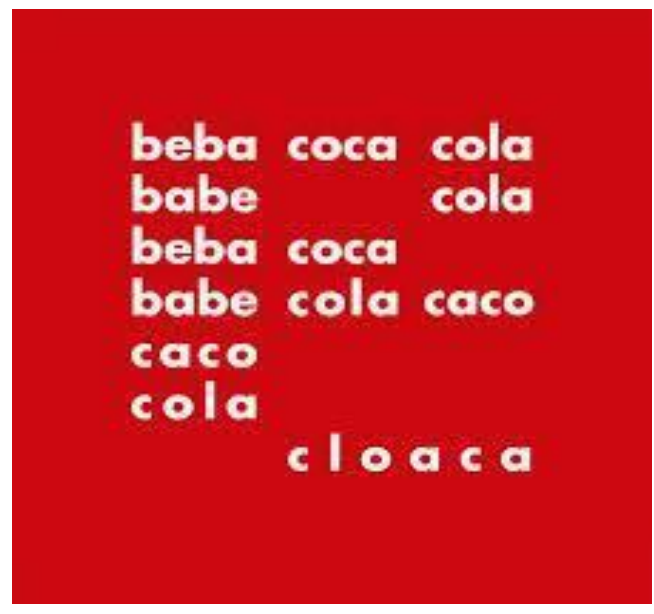

Figura 1 - "beba coca cola".

El concretismo pretendía alcanzar el carácter "verbivocovisual" de la poesía (verbal, vocal y visual) y capturar la materialidad del lenguaje, tal como lo expresaron en su manifiesto "Planopiloto para poesia concreta" (1958/1975). Se lee en el texto la tensión de las palabras-cosas en el espacio-tiempo, es decir, la ejecución del proyecto concreto trazado en los manifiestos. Por eso, si hablamos de crítica social no lo hacemos únicamente en el plano del lenguaje, sino también en una dimensión visual y sonora. Parece casi un 'accidente' o, mejor dicho, un silogismo lógico: solo modificando unas pocas letras (en tanto marcas gráficas, grafemas), "coca cola" nos lleva a "cloaca". Si el anagrama es la transposición de dos palabras o frases diferentes a partir del intercambio de los mismos elementos, podemos inferir que ya "cloaca" estaba cifrado en "coca cola". Este mecanismo permite ligar "coca cola" con "coca" y "caco" y a "beba" con "babe". En el caso de "coca", podría hacer referencia a la droga "cocaína" y dar lugar entonces, a un juego de asociaciones entre la gaseosa, la adicción y lo que eso podría desencadenar. Uno de los significados posibles para "caco" es "pedazo o trozo", palabra que remite a la materialidad del objeto, las partes o fragmentos de los que está hecho. Otro es "desastre" o "ruina", es decir, lo que queda, los restos. En la mitología romana, Caco (Cacus en latín), se traducía como malo o malvado, y era un gigante que escupía fuego y humo, hijo de Hefesto; además solía robar, y por eso su nombre fue y sigue siendo sinónimo de ladrón (Grimal, 2010). Asimismo, CaCO es el compuesto químico 'carbonato de calcio'. Leyendo los envases de la gaseosa, advertimos que el carbonato o el agua carbonatada es uno de sus ingredientes, en teoría, el que logra que el líquido sea burbujeante. Como vemos, las posibilidades semánticas son amplias y variadas, y a su vez, presentan distintos niveles. Algunas connotaciones son más evidentes y familiares y otras, como el gigante mítico, conectan con saberes literarios o culturales. 
Siguiendo con el análisis, "babe" viene del verbo "babar", de babear, babosear o llenar de baba. "Beba" y "babe" se alternan en el poema como dos acciones que transcurren de manera consecutiva; su repetición aporta ritmo a la lectura, que se ve alterada (en su acepción convencional) no solo por los sonidos que se reiteran sino también por la disposición espacial. "Cloaca" se destaca porque es la palabra final y se encuentra demarcada por un espacio en blanco inicial. En este punto, el tono crítico adquiere vigor: la cloaca remite inevitablemente a lo podrido, al excremento, la suciedad, los residuos. Estas vinculaciones semánticas se oponen radicalmente a la idea de placer o goce a la que las publicidades apuntan cuando promocionan la Coca-Cola. Klaus Müller-Bergh $(1979$, p. 25$)$ relaciona al poema de Pignatari con "La United Fruit Co" (del extenso poemario Canto general) de Pablo Neruda, inscribiéndolo así en una serie de textos de sesgo antiimperialista, que a través de la caracterización negativa de las compañías norteamericanas denunciaron la colonización económica y cultural oculta, muchas veces, en los augurios de progreso o desarrollo. Santoro también escribió uno llamado "Shell" (1975) donde se vincula a la multinacional de hidrocarburos con los crímenes y la miseria provocada.

Por último, no es ocasional el uso de la tipografía "futura-bold", sino que se conecta con lo dicho anteriormente, al igual que la elección por el color rojo para el fondo (color identitario de la marca) y las letras blancas. ${ }^{10}$ Aguilar dice que este elemento fue desatendido por la crítica, pero que revela la estrategia vanguardista de dislocación utilizada por la poesía concreta más ortodoxa, es decir, un intento de acercar la poesía a la vida cotidiana, y trasladar a ella postulados de las 'artes aplicadas' que podrían parecer extraños o ajenos, como las publicidades de Madison Avenue. Aguilar continúa:

La tipografía saca al poeta -mediante su principio reproductivo- del mundo artesanal y lo enfrenta a las nuevas posibilidades tecnológicas de la escritura [...] En los poemas concretos, la tipografía "futura bold" fue convertida en el tipo modernista por excelencia, sin ornamentos y estrictamente funcional. Es una letra sin serif y sin adornos, que privilegia su economía y su transparencia en relación con otras tipografías. Tiene lo mínimo para ser entendida, tiene lo básico para funcionar (2003, p. 245-248).

Esta tipografía se gesta en el contexto del furor de la Bauhaus en Alemania (en la llamada "Nueva Tipografía"), donde no se distinguían las "bellas artes" de las "artes aplicadas". En este sentido, la grafía no es un mero recurso de escritura sino técnica, de diseño, artística y, por ende, forma parte del armado textual; se vincula además con el criterio de "utilidad", ligado a este tipo de campos. El poema otorga importancia al ojo del lector/espectador, al potencial de la visualidad. De hecho, la poesía visual (que entronca de algún modo con esta valorización del ojo) tiene un alcance bastante extenso en Latinoamérica, desde las vanguardias de la década del 20 hasta su afianzamiento en los 70-80 con las bienales de Poesía Visual y Experimental, a cargo del Núcleo Post-Arte mexicano y la $1^{\text {a }}$ Muestra Internacional de Poesía Visual, organizada por Philadelpho Menezes en São Paulo en 1988. Todavía en la actualidad seguimos las pistas de este tipo de expresiones que adquieren mayor relevancia en el contexto de una cultura marcadamente visual como la nuestra, dominada por los artefactos electrónicos y las pantallas. Del mismo modo, el poema de Pignatari desacomoda la mirada, provoca extrañamiento (o desautomatización, tal como plantearon los formalistas rusos) en relación al ícono convencional de Coca-Cola y sus clichés publicitarios. Al mismo tiempo, es un acto de antropofagia poética (y así resuena Oswald de Andrade y su manifiesto), porque toma al referente "Coca", lo mastica, lo deglute y da lugar a otro: "cloaca".

El poema de Santoro, "tome coca cola", empieza con una interpelación, una búsqueda de complicidad:

usted sabe

que el país no anda

\footnotetext{
${ }^{10}$ Este modelo de tipografía se conocía como "paloseco" o "sin remates" (los caracteres carecen de las pequeñas terminaciones llamadas remates, gracias o serifas) y fue creada por Paul Renner en 1927. Se movió dentro de la llamada "Nueva tipografía" alemana. Se trata de una tipografía con bases racionalistas y fundamentada sobre formas geométricas (círculos, triángulos y cuadrados) (Meggs y Purvis, 2015).
} 


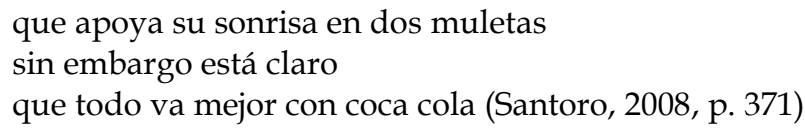

Aparece en el cuerpo textual la segunda persona ya utilizada en el título y se establece así una continuidad, un diálogo en tono confesional. Se apela al conocimiento previo de la situación que se plantea. A través de la personificación y del uso de la metáfora (o imagen) que podríamos, provisoriamente, identificar como surrealista, se muestra el estado del país (de uno en particular, de cualquiera). Expresiones coloquiales como "usted sabe" y "está claro" proyectan una entonación confidencial y refuerzan la idea de que el sujeto ya está al tanto de que "el país no anda" y de cómo sobrellevar dicha realidad. El último verso adopta el tono del slogan o jingle publicitario, una frase pegadiza y fácil de recordar. Pero en el contexto del poema igualmente se lee el tono irónico, a partir del contraste entre el problema (un país que no anda y lo que ello puede ocasionar) y la solución entusiasta del slogan (tomar una gaseosa). La Coca-Cola es ahora anestesia o ¿cómo podría modificarse un estado de cosas bebiendo Coca? La búsqueda del bienestar propio, la preeminencia de la indiferencia y la frivolidad tal vez sean causas y no consecuencias. En efecto, se puede leer también en sentido inverso: porque todo va mejor con Coca-Cola es que (en parte) el país no anda. Tomar Coca representa un momento efímero e individual, una apuesta por despreocuparse, aunque sea un rato. Por otro lado, "tomar" puede significar, al menos en el español rioplatense, apropiarse o adueñarse de, ocupar, conquistar. Quizás elegir esta opción léxica (frente a "beber") no tenga solo que ver con una cuestión coloquial ("tomar" es más utilizado) y se relacione también con la dimensión política que adquiere esa palabra. Tomar las fábricas, tomar las armas, tomar las calles, son llamamientos recurrentes durante esos años y aunque no hay más evidencia de este vínculo en el poema, al menos queda abierto el interrogante.

No negociable fue un poemario escrito en los umbrales de la última dictadura cívico militar de 1976. Su título también juega con los enunciados vinculados a la Coca-Cola. Mientras que los productos comerciales llevan la leyenda "No retornable", el "No negociable", aunque tiene un parentesco fonético, conlleva un significado diametralmente opuesto. La poesía no es aquello que se compra y se vende, se usa y se tira, sino que permanece impoluta o intenta no someterse a la lógica y las imposiciones del mercado: responde solo a sí misma. Por lo tanto, el espacio poético se abre como una forma de resistencia contra quienes pretenden mirar hacia otro lado. La poesía no se evade, no negocia, no se rinde ante la seducción publicitaria. Denuncia que ese país "no anda". Y así se configura a lo largo de la obra un escenario urbano oscuro y asfixiante, -tanques de guerra, cadáveres, desaparecidos, torturas, censura y hambre- que convive simultáneamente con carteles y calcomanías que presagian felicidad o reclaman sonrisas. En otro poema, titulado "saciedad del consumo", leemos:

mujer
ejecutivo
coca-cola
usa
consolador
botella
Pepsi (Santoro, 2008, p. 371)

A modo de lista, sin conjunciones ni artículos, se construye una escena que a partir de la aparición del sustantivo "consolador" deviene erótica. La botella de gaseosa (ahora de la competencia) se vuelve un objeto de placer sexual. Pero si atendemos al enfrentamiento de las dos marcas (Coca y Pepsi) y al juego de palabras que se produce en el título, entonces el deseo (su "saciedad") es consumir el producto del 'enemigo'. Es habitual en la poesía de Santoro la utilización de imágenes eróticas o sensuales (a veces vinculadas también con lo escatológico) para resaltar el lado salvaje o pulsional de las acciones cotidianas, un mundo secreto que parece existir en paralelo al habitual, donde todo se pretende monótono y apacible. En su poética, la 'verdad' o la posibilidad de acercarse a ella - se esconde en un detalle minúsculo, un movimiento que pasaría desapercibido entre los grandes acontecimientos: una mariposa muerta, un hombre 
durmiendo, una taza de café o de té. Finalmente, llama la atención la palabra ubicada en el centro del poema ("usa"), que nos remite no solo al verbo "usar" sino también a la abreviatura de los Estados Unidos (United States of America). Si observamos el término en esta última acepción, entonces "usa" puede ser interpretado como consolador. El poema pareciera dejarse leer en todas las direcciones y sentidos posibles - gracias a la ausencia de conectores, artículos, pronombres, etc. - como los juegos de 'unir con flechas' o los crucigramas.

Las tres figuraciones de Coca-Cola como cloaca, anestesia social y consolador nos permiten hablar de una apropiación crítica del material poético y no únicamente de un gesto vanguardista, que a esas alturas ya estaba bastante automatizado y difundido. No obstante, es necesario marcar algunas diferencias. El concretismo establece un diálogo más palpable con el sistema literario y teórico europeo, no solo en sus textos sino además en las resonancias explícitas que el movimiento mencionaba en sus manifiestos y a los que adscribía. El nombre que designa al grupo fue acuñado en 1930 por van Doesburg y luego utilizada por otros artistas como Arp y Kandinsky. En su primera época, reivindican a Ezra Pound, E.E Cummings, a Mallarmé y al Joyce de Finnegans Wake, además de a los autores brasileros (João Guimarães Rosa, João Cabral de Melo Neto y Oswald de Andrade). Pignatari expone los artificios del lenguaje y de las imágenes, disloca sus reglas, su convencionalidad; hay una voluntad de transgresión evidente en todos los planos (fonético, morfológico, sintáctico, semántico, visual) no para representar o figurar (como por ejemplo en los caligramas de Apollinaire), sino conceptualizar. Santoro es irreverente, pero traza un recorrido distinto, con otros motivos e inflexiones. Aunque podamos pensar su poética en clave vanguardista, sería en un sentido menos estricto del término, es decir, como mera ruptura de algunas formas tradicionales. Esto es válido y debemos decir también que en sus últimos libros (No negociable, Series y 20 poemas negros sin filtro) ese matiz se acentúa. Aun así, esto responde más a una cercanía con el coloquialismo y a la búsqueda de una poesía popular, sin demasiadas filiaciones o préstamos. Daniel Freidemberg ubica a Santoro dentro de esta tendencia, que caracteriza como:

Un ideal que la escritura de muchos poetas parece perseguir: que la diferencia entre un poema y la transcripción de un tramo de conversación no esté en el vocabulario, en la temática o en los modos expresivos sino en una mayor destreza en la selección de los materiales y en su administración, en función de una mayor elocuencia y de una cierta belleza en los resultados (Freidemberg, 1999, p. 189).

El acercamiento ocurrió en el marco de un programa estético y político (en torno al grupo Barrilete y al frente cultural FATRAC de los que formó parte), ${ }^{11}$ que pretendía ampliar el público lector o, mejor dicho, incorporar a los sectores más populares. No negociable se abre con un poemaepígrafe ("Declaración jurada") que resume, de alguna manera, su ética poética: "Si mi poesía no ayuda a cambiar la sociedad no sirve para nada" (Santoro, 2008, p. 358). Es necesario, en ese sentido, hacer una distinción entre "beba coca cola" y el tono que adopta el texto de Santoro. El poema de Pignatari, a secas, sin contextualizarlo en ese primer momento del concretismo, puede ser analizado en clave antiimperialista $y$, de hecho, encontramos varios elementos que contribuyen a esa lectura. Pero la poesía concreta se vio a su vez - al menos durante los 50 seducida por la llegada de esos objetos novedosos o las nuevas voces publicitarias que comenzaron a resonar en las ciudades. ${ }^{12}$ De ahí que una influencia notable durante ese periodo haya sido el futurismo, en especial el ruso, encarnado en la figura de Maiakóvski, así como también la geometría, la arquitectura y el diseño gráfico (artes vinculadas con el consumo, las máquinas y la industria). Para Heloisa Buarque de Hollanda (2004, p. 45-46), la intención "didáctica" o el foco en tópicos de carácter político va a emerger recién entrados los 60, cuando la

\footnotetext{
${ }^{11}$ Barrilete fue una revista y grupo editorial que se llevó adelante entre 1963 y 1974 (Bonano, 2013). Por otro lado, el Frente Antiimperialista de Trabajadores de la Cultura, fue un frente cultural ligado al Partido Revolucionario de los Trabajadores, surgido en 1968 y hay indicios de su continuidad hasta 1971 (Longoni, 2005).

${ }^{12}$ Entendemos que el concretismo en Brasil fue una tendencia con distintos ritmos a lo largo del tiempo y que las producciones de sus autores presentan matices y particularidades. Ya para mediados de la década del 60 , los concretos darán un giro hacia lo que se conoció como el "salto participativo", donde se volcaron más hacia tópicos vinculados con la realidad social: huelgas, hambre, conflictos laborales, entre otros (Arantes, 2000).
} 
vanguardia se encuentre con una coyuntura social violenta y dictatorial. Hasta entonces, el poema es pensado y planteado como un objeto, un objeto de goce, de dimensión lúdica (elemento que se aprecia en "beba coca cola") y de consumo por parte del espectador/lector. Esta distinción nos sirve para matizar el grado de crítica presente en el poema de Pignatari y también para establecer una diferencia entre los 60 y los 70. Santoro, quince años después, recupera algunas de las estrategias formales que vemos en Pignatari y dialoga igual que él con las publicidades de CocaCola, pero con una carga ideológica más aguda. En su ironía - cargada de desencanto y pesimismo -, la denuncia contra la evasión a la que quieren conducir a la sociedad, cobra fuerza, se vuelve menos sutil y mucho más explícita. Recordemos que ya para los setenta el clima revolucionario, incluso las expectativas sociales respecto del proyecto modernizador, va a verse mitigado fuertemente por el avance de la represión.

En conclusión, podemos decir que tanto Santoro como Pignatari intervienen más allá del poema, es decir, ponen a prueba sus aparentes límites y lo expanden hacia otros aspectos como el consumo, la cultura, la sociedad de masas y la política. Aunque cada uno practica una modulación distinta, en ambos hay una experimentación lúdica con la propia lengua y la forma del texto, un sesgo crítico y una problematización acerca de la relación entre discurso publicitario y literatura. A pesar de que no hay registros de que se hayan leído o conocido, creemos relevante continuar investigando acerca de las resonancias del concretismo y el conceptualismo en el último libro de Santoro y en sus papeles póstumos.

\section{Referências}

AGUILAR, Gonzalo (2003). Poesía concreta brasileña: las vanguardias en la encrucijada modernista. Rosario: Beatriz Viterbo.

ALTAMIRANO, Carlos (1998). Desarrollo y desarrollistas. Revista Prismas, Buenos Aires, n. 2, p. 75-94.

ANTELO, Raúl (2013). Para una archifilología latinoamericana. Cuadernos de Literatura, Bogotá, v. 17, n. 33, p. 253-281.

ARANTES, Otilia Beatriz Fiori (2000). Después de las vanguardias (años 60 y 70). In: AMANTE, Adriana; GARRAMUÑO, Florencia (org.). Absurdo Brasil: polémicas en la cultura brasileña. Selección, traducción y prólogo de Adriana Amante y Florencia Garramuño. Buenos Aires: Biblos. p. 219-242.

BAUDRILLARD, Jean (2009). La sociedad de consumo. Sus mitos, sus estructuras. Madrid: Siglo XXI.

BAUDRILLARD, Jean (2016). El sistema de los objetos. 22 ed. en español. México: Siglo XXI.

BAUMAN, Zygmunt (2007). Vida de consumo. México: Fondo de Cultura Económica.

BONANO, Mariana (2013). El poeta del pueblo / la poesía para el pueblo: en torno al proyecto de El Barrilete (primera época). La Plata: Orbis Tertius, v. 18, n. 19, p. 113-125.

BÜRGER, Peter (2000). Teoría de la vanguardia. 3. ed. Barcelona: Península.

CAMPOS, Augusto de; PIGNATARI, Décio; CAMPOS, Haroldo de (1958/1975). Plano-piloto para poesia concreta. In: CAMPOS, Augusto de; PIGNATARI, Décio; CAMPOS, Haroldo de. Teoria da poesia concreta. Textos críticos e manifestos 1950-1960. São Paulo: Duas Cidades. p. 156-158.

DEBORD, Guy (2006). La sociedad del espectáculo. Barcelona: Anagrama.

FREIDEMBERG, Daniel (1999). Herencias y cortes. Poéticas de Lamborghini y Gelman. In: JITRIK, Noé; CELLA, Susana (dir.). Historia crítica de la literatura argentina: la irrupción de la crítica. Buenos Aires: Emecé.

GILMAN, Claudia (2003). Entre la pluma y el fusil: debates y dilemas del escritor revolucionario en América Latina. Buenos Aires: Siglo XXI.

GRIMAL, Pierre (2010). Diccionario de mitología griega y romana. Buenos Aires: Paidós. 
HOLLANDA, Heloisa Buarque de (2000). La participación comprometida en el furor de los años 60. In: AMANTE, Adriana; GARRAMUÑO, Florencia (org.). Absurdo Brasil: polémicas en la cultura brasileña. Selección, traducción y prólogo de Amante, Adriana y Garramuño, Florencia. Buenos Aires: Biblos. p. 219-242.

HOLLANDA, Heloisa Buarque de (2004). Impressões de viagem - CPC, vanguarda e desbunde: 1960/70. Rio de Janeiro: Aeroplano.

LONGONI, Ana (2014). Vanguardia y revolución: arte e izquierdas en la Argentina de los sesenta-setenta. Buenos Aires: Ariel.

LONGONI, Ana (2005). El FATRAC, frente cultural del PRT/ERP, Lucha Armada, Buenos Aires, n. 4.

MARX, Karl (2010). El capital. Tomo I. Traducido al español por Pedro Scaron. Madrid: Siglo XXI.

MEGGS, Philip; PURVIS, Alston W. (2015). La Bauhaus y la Nueva Tipografía. Historia del diseño gráfico. Barcelona: RM Verlag. p. 310-336.

MÜLLER-BERGH, Klaus (1979). Feijoada, Coke \& the Urbanoid: Brazilian Poetry since 1945. World Literature Today, Oklahoma, v. 53, n. 1, p. 22-30.

PENDERGRAST, Mark (2000). For god, country and Coca Cola. New York: Basic Books.

PIGNATARI, Décio (2004). “beba coca cola”. In: PIGNATARI, Décio. Poesia pois é poesia. 1950-2000. São Paulo: Ateliê.

PORRÚA, Ana (2013). La imaginación poética: entre el archivo y la colección. In: VI JORNADAS INTERNACIONALES DE FILOLOGÍA Y LINGÜÍSTICA Y PRIMERAS DE CRÍTICA GENÉTICA “LAS LENGUAS DEL ARCHIVO". Actas... La Plata: Universidad Nacional de La Plata. Disponible en http://www.memoria.fahce.unlp.edu.ar/library? $\mathrm{a}=\mathrm{d} \& \mathrm{c}=$ eventos\&d=Jev3875. Último acceso: 23 de febrero 2018.

SANTORO, Roberto (2008). No negociable. Obra poética completa. Buenos Aires: Razón y Revolución.

VÁSQUEZ, Rafael (2003). Informe sobre Santoro. Aproximación bio-bibliográfica sobre el poeta Roberto Jorge Santoro. Buenos Aires: Libros de Tierra Firme.

WARHOL, Andy (1975). The philosophy of Andy Warhol: from A to B and back again. New York: Harcourt Brace Jovanovich. 